\title{
Acute Myocardial Infarction Followed by Acute Necrosis Cholecystitis and Sepsis: Treatment in Dilemma
}

\author{
Gui Ling Ma $\mathrm{Ma}^{\mathrm{a}}$, Qiang $\mathrm{He}^{\mathrm{b}}$, Li Xin $\mathrm{Li}^{\mathrm{b}}$, Mu Lan Jinc, Wen Shu Zhao ${ }^{\mathrm{a}}$, Zhu Hua Nia, \\ Zhi Yong Zhang, Lin Zhang, d
}

\begin{abstract}
Studies showed a high risk of major adverse cardiac events if a non-cardiac surgery was performed early after coronary stenting. There is no literature about non-cardiac surgery early after acute myocardial infarction. We present a 66 years old woman suffered from fever and shiver on the 6th day after coronary stenting for acute myocardial infarction with continuously use of dual antiplatelet and anticoagulant drugs. Immediately after acute cholecystitis and gall stone were diagnosed by abdominal ultrasonography on the 7th day, we performed an emergency open cholecystectomy. The pathological examination showed acute hemorrhagic and necrosis cholecystitis and inflammation of surrounding tissues. Three days later, clopidogrel and aspirin was reinstituted to her with no major adverse cardiac events or surgery complications.
\end{abstract}

Keywords: Acute Myocardial Infarction; Acute Cholecystitis; Antiplatelet Therapy; Cholecystectomy

\section{Introduction}

More than 10 million people have heart attack every year worldwide and the incidence of myocardial infarction (MI)

Manuscript accepted for publication November 24, 2011

${ }^{a}$ Department of Heart Center, Beijing Chao-Yang Hospital, Capital Medical University, \#8 Gong-Ti South Road, Beijing, 100020, China

${ }^{b}$ Department of Hepatobiliary Surgery, Beijing Chao-Yang Hospital, Capital Medical University, \#8 Gong-Ti South Road, Beijing, 100020, China

${ }^{\mathrm{c}}$ Department of Pathology, Beijing Chao-Yang Hospital, Capital Medical University, \#8Gong-Ti South Road, Beijing, 100020, China

${ }^{\mathrm{d}}$ Corresponding author: Lin Zhang.

Email: linzhangpeking@yahoo.com.cn

doi: $10.4021 / \mathrm{jmc} 450 \mathrm{w}$ is rising in many developing countries [1]. The benefits of reperfusion therapy and dual antiplatelet therapy have been clearly demonstrated [2]. In the literature on perioperative use of antiplatelet agents is a warning signal when prescribed for secondary prevention after MI or coronary stenting. Besides, studies showed a high risk of MACEs if a non-cardiac surgery was performed early after coronary stenting especially less than two to six weeks [3-5]. We present a case diagnosed as acute hemorrhagic and necrosis cholecystitis on the 7th day after coronary stenting for acute MI especially she has been receiving aspirin and clopidogrel.

\section{Case Report}

A 66 years old woman was admitted to the hospital with sudden onset of palpitation and sweating for one hour after activities. She had a history of hypertension for 10 years and cerebral infarction for 5 years. Besides she received bowel resection for intestinal obstruction 30 years ago. According to the symptom, electrocardiogram and cardiac enzymes, the diagnosis was acute inferior, posterior and right ventricular MI [6]. Emergency coronary angiography showed the proximal of right coronary artery occlusion completely and we placed a drug-eluting stent there. Then she was admitted to coronary care unit, where continuous infusion of tirofiban, a glycoprotein (GP) IIb/IIIa inhibitor, $(0.1 \mu \mathrm{g} / \mathrm{kg} / \mathrm{min})$ for 72 hours, oral clopidogrel $(75 \mathrm{mg} / \mathrm{d})$ plus aspirin $(100 \mathrm{mg} / \mathrm{d})$, subcutaneous fragmin 6150AXaIU/12 hours.

Six days later, she shivered violently and the body temperature rose to $39.4{ }^{\circ} \mathrm{C}$. Laboratory test showed the leukocyte count of $13.36 \times 10^{9} / \mathrm{L}$, the neutrophil account for $91.9 \%$. On the 7th day, she shivered again with the temperature rose to $40.8^{\circ} \mathrm{C}$. Physical examination was normal except for right upper abdominal tenderness. Abdominal ultrasonography showed gallstone and acute cholecystitis (Fig. 1).

Early laparoscopic cholecystectomy is considered the first choice for most cholecystitis patients [7]. For severe acute cholecystitis, urgent management of organ dysfunction and severe local inflammation by cholecystectomy should be carried out [7]. For this patient, surgery can remove the focus of infection fundamentally. Given she had suffered from 


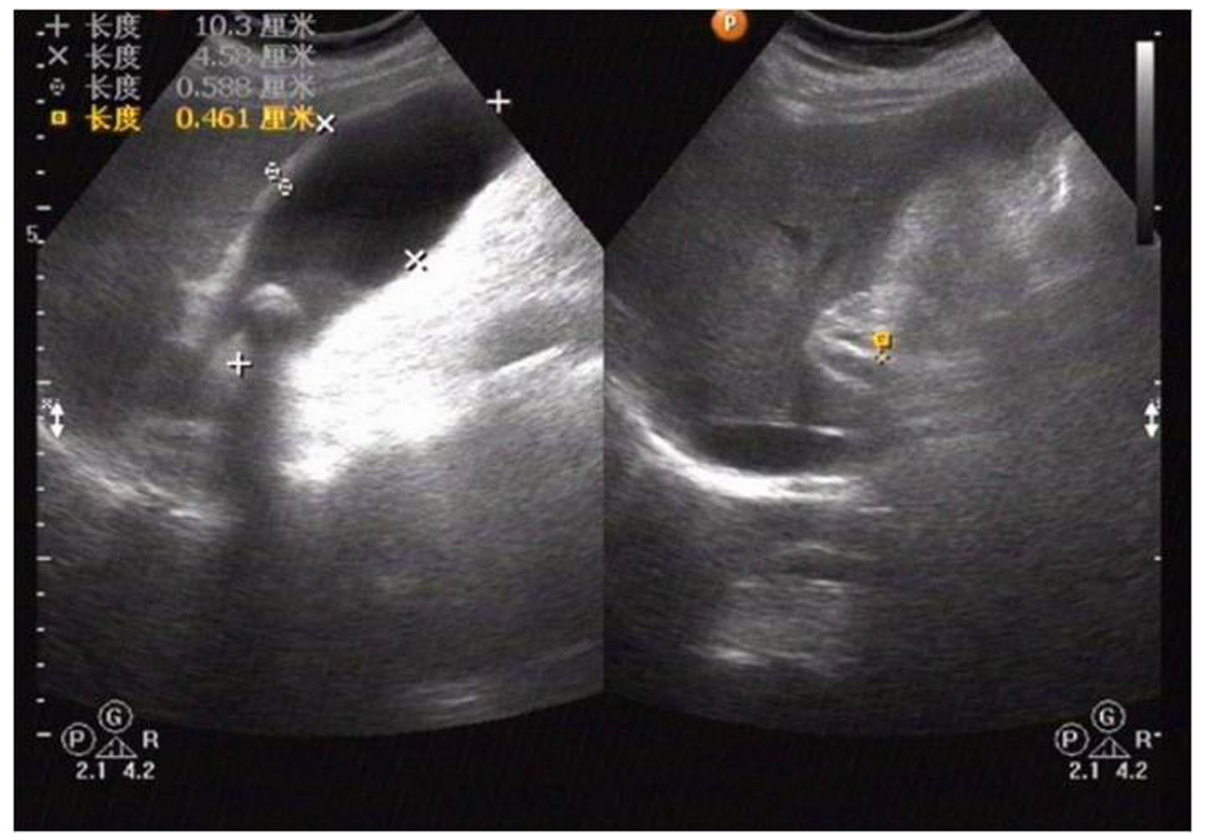

Figure 1. Abdominal ultrasonography shows gallstone and acute cholecystitis: the size of gallbladder is $10.3 \mathrm{~cm} \times 4.6 \mathrm{~cm}$, slightly larger gallbladder with gallbladder wall thickening, and hypoechoic gallbladder.

acute MI 7 days ago especially she had been receiving dual antiplatelet therapy, she had a high risk of MACEs, bleeding and other adverse events during the perioperative period of cholecystectomy. Besides she received bowel resection 30 years ago, open cholecystectomy would be necessary. An emergency open cholecystectomy was performed that day with no blood transfusion. The pathological conclusion was acute hemorrhagic and necrosis cholecystitis and inflammation of gallbladder surrounding tissues (Fig. 2).

After the operation, we prescribed fragmin 6150AXaIU/12

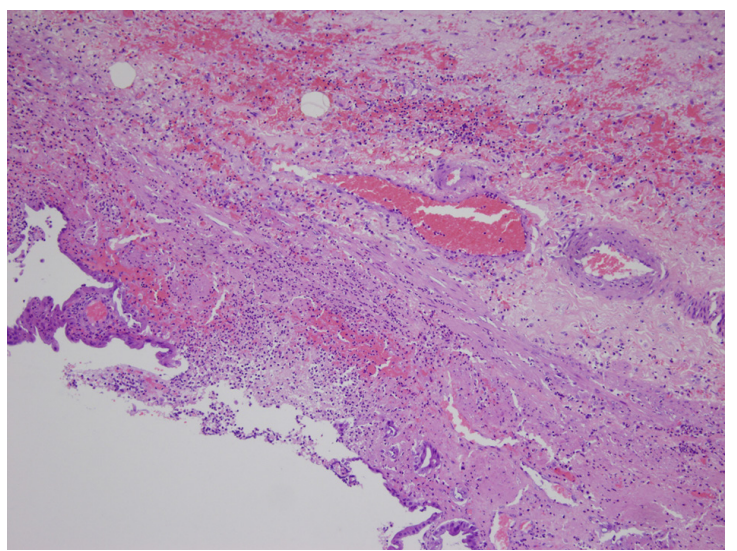

Figure 2. Microscopy ( $\times 400$ ) of histology of gallbladder shows a large number of neutrophils exudation in all layers of gallbladder wall with varying degrees of tissue necrosis, vascular congestion, neutrophils adherence and extensive hemorrhage in the gallbladder wall. hours with no aspirin or clopidogrel. The drainage was 100 $\mathrm{mL}$ and $30 \mathrm{~mL}$ respectively on the first two days and the drainage tube was removed on the third day. One day later, clopidogrel $(75 \mathrm{mg} / \mathrm{d})$ and aspirin $(100 \mathrm{mg} / \mathrm{d})$ was reinstituted. She was discharged on the 8th day after operation without MACEs or surgery complications with a follow-up at the cardiology department for one year.

\section{Discussion}

There is no literature about cholecystectomy early after acute MI. An increased risk of MACEs for non-cardiac surgery early after coronary stenting has been suggested and the most important reason is stent thrombosis $[3-5,8]$. It is reported that the mortality was $32 \%$ in patients subjected to surgery less than 2 weeks from coronary stenting [3]. Among the 40 patients, 2 of them underwent cholecystectomy with no MACEs. Wilson and associates found the increased risk persisted for 6 weeks and the mortality was 4.8\% [4]. Among the 207 patients studied, 2 of them underwent abdominal surgery less than 6 weeks and both suffered from MACEs. Reddy and Vaitkus reviewed all the 56 cases of coronary stenting with subsequent surgery, 8 developed MACEs with none when surgery performed after 6 weeks [5]. Schouten and associates found in patients undergoing early surgery, discontinuation of antiplatelet therapy during the perioperative period maybe a major cause of increasing in MACEs, mainly result from stent thrombosis [6].

In conclusion, whenever possible non-cardiac surgery 
should be postponed to 6 weeks after coronary stenting [4, 5]. Emergency surgery is an alternative method for acute MI patient accompanied by acute necrosis cholecystitis and sepsis. Further prospective clinical studies are needed to define whether surgeries can be performed safely with minimum interruption or continuous of antiplatelet therapy for acute MI patients.

\section{Grant}

No.

\section{Conflict Interest}

The authors declare no conflict of interest.

\section{References}

1. Yusuf S, Reddy S, Ounpuu S, Anand S. Global burden of cardiovascular diseases: part I: general considerations, the epidemiologic transition, risk factors, and impact of urbanization. Circulation. 2001;104(22):2746-2753.

2. Chen ZM, Jiang LX, Chen YP, Xie JX, Pan HC, Peto $\mathrm{R}$, Collins $\mathrm{R}$, et al. Addition of clopidogrel to aspi- rin in 45,852 patients with acute myocardial infarction: randomised placebo-controlled trial. Lancet. 2005;366(9497):1607-1621.

3. Kaluza GL, Joseph J, Lee JR, Raizner ME, Raizner AE. Catastrophic outcomes of noncardiac surgery soon after coronary stenting. J Am Coll Cardiol. 2000;35(5):12881294.

4. Wilson SH, Fasseas P, Orford JL, Lennon RJ, Horlocker T, Charnoff NE, Melby S, et al. Clinical outcome of patients undergoing non-cardiac surgery in the two months following coronary stenting. J Am Coll Cardiol. 2003;42(2):234-240.

5. Reddy PR, Vaitkus PT. Risks of noncardiac surgery after coronary stenting. Am J Cardiol. 2005;95(6):755-757.

6. Thygesen K, Alpert JS, White HD. Universal definition of myocardial infarction. J Am Coll Cardiol. 2007;50(22):2173-2195.

7. Yamashita Y, Takada T, Kawarada Y, Nimura Y, Hirota M, Miura F, Mayumi T, et al. Surgical treatment of patients with acute cholecystitis: Tokyo Guidelines. J Hepatobiliary Pancreat Surg. 2007;14(1):91-97.

8. Schouten O, van Domburg RT, Bax JJ, de Jaegere PJ, Dunkelgrun M, Feringa HH, Hoeks SE, et al. Noncardiac surgery after coronary stenting: early surgery and interruption of antiplatelet therapy are associated with an increase in major adverse cardiac events. J Am Coll Cardiol. 2007;49(1):122-124. 